\title{
COLOSSAL BREED AND BACKLASH OF THE 'SESAME STREET': BRUNT OF COVID-19 PANDEMIC IN THE 'HIGH-TECH' ERA OF LEARNING ON CHILDREN AND ADOLESCENTS AND SUGGESTIONS
}

\author{
Bichitra Nanda Patra ${ }^{1}$, Kumari Rina $^{2}$ \& Susanta Kumar Padhy ${ }^{2}$ \\ ${ }^{1}$ Department of Psychiatry, All India Institute of Medical sciences, New Delhi, India \\ ${ }^{2}$ All India Institute of Medical sciences, Bhubaneswar, Odisha, India
}

received: 5.2.2021;

revised: 27.3.2021;

accepted: 5.4 .2021

\section{SUMMARY}

The COVID-19 pandemic necessitated the closure of various academic institutions, leaving online learning the only option for continuity of education and curricular activities among children and adolescents. It is unclear whether the adoption of online learning will persist in the post-pandemic period. However, enhanced exposure to gadgets impacts the socio-emotive-adaptive development of young children. It sprouts various short-term as well as long-term deleterious physical and mental health effects among children and adolescents. Research has focused mainly on the epidemiology, risks modeling, pathophysiology, and clinical features of SARS-CoV-2, but the impact of increased exposure to gadgets and technology due to online learning activity and the "digital new-norm" has largely been unnoticed. The enforced/self-quarantine leading to less outdoor activities during this pandemic, may have a cumulative poor health consequence. Early detection and management of those at risk and signs and symptoms of these adverse health effects are important. Awareness regarding these ill-effects on this vulnerable group is relevant for parents, guardians, teachers, mentors, health-care providers, and policy-makers.

Key words: online classes - digital learning environment - virtual learning - screen-time and hazards - exposure to internet content

\section{INTRODUCTION}

COVID-19 pandemic has funneled the entire world to a virtual platform, including scholastic and nonscholastic learning. India's first lockdown evidenced a screen-time spike by $100 \%$ among children in the agegroup of 5 to 15 year, spending an additional five hours online (Verma 2020). However, online-learning furtherance during post-pandemic era and its impact on socioemotional-adaptive functioning and learning among children is unknown.

\section{DELETERIOUS HEALTH-EFFECTS OF HIGH SCREEN-TIME}

Increased screen-time is associated with wide-array of non-communicable diseases. The burden of screen-time varied from $21 \%$ to $98 \%$ in the middle-income, and $10 \%$ to $93.7 \%$ in the high-income countries (Kaur et al. 2019). Children spending over three hours/day on screen-time have heightened risk of weight gain, adiposity, insulin-resistance, and thus, type- 2 diabetes, as compared to peers spending one hour or less of screen-time daily (Nightingale et al. 2017). The higher levels of physical activity do not compensate for the negative effects of screen-time (Domingues-Montanari 2017). Sedentary life-style, especially during COVID-19-pandemic, may elevate the risks for hypertension. Less sunlight exposure may aggravate existing vitamin-D deficiency among children (Bhargava
2020). The mobile phone radiation can alter the heart rate and its variability; ECG and EEG changes (Ahamed et al. 2008, Roggeveen et al. 2015). Among children, the mobile-phone usage owes to greater radio-frequency energy deposition in the brain (two folds) and bone marrow of the skull (ten folds). Microwave emissions may escalate the risk of brain tumors and melanoma (Hardell et al. 2009). Digital screen-time during COVID-19 pandemic may cause myopia boom (Wai Wong at al. 2020). Prolonged exposure to mobile-phone may increase the hearing threshold of the exposed ear (Das et al. 2017).

Childhood and adolescence are sensitive periods in which neurobiological systems (like hypothalamic-pituitary-adrenal (HPA) axis and dopaminergic circuitries) develop, making them vulnerable to insult. Excessive screen-time stimulates these circuitries disproportionately. Among preschoolers, it hampers the development of cognitive abilities (including attention, working memory, executive functions, intelligence, visuo-spatialverbal development), social and emotional (self-regulation and prosocial behavior) abilities (Oswald at al. 2020). An increase in 30 minutes/day in mobile-media usage among toddlers is associated with a 2.3 folds greater risk expressive speech delays, communication delays (lie use of gestures, eye gaze, etc.). Excessive screen-time leads to developmental delays, rather than the other way around-negating the notion, that children with developmental delays might receive more screentime to manage their problematic-behavior. 


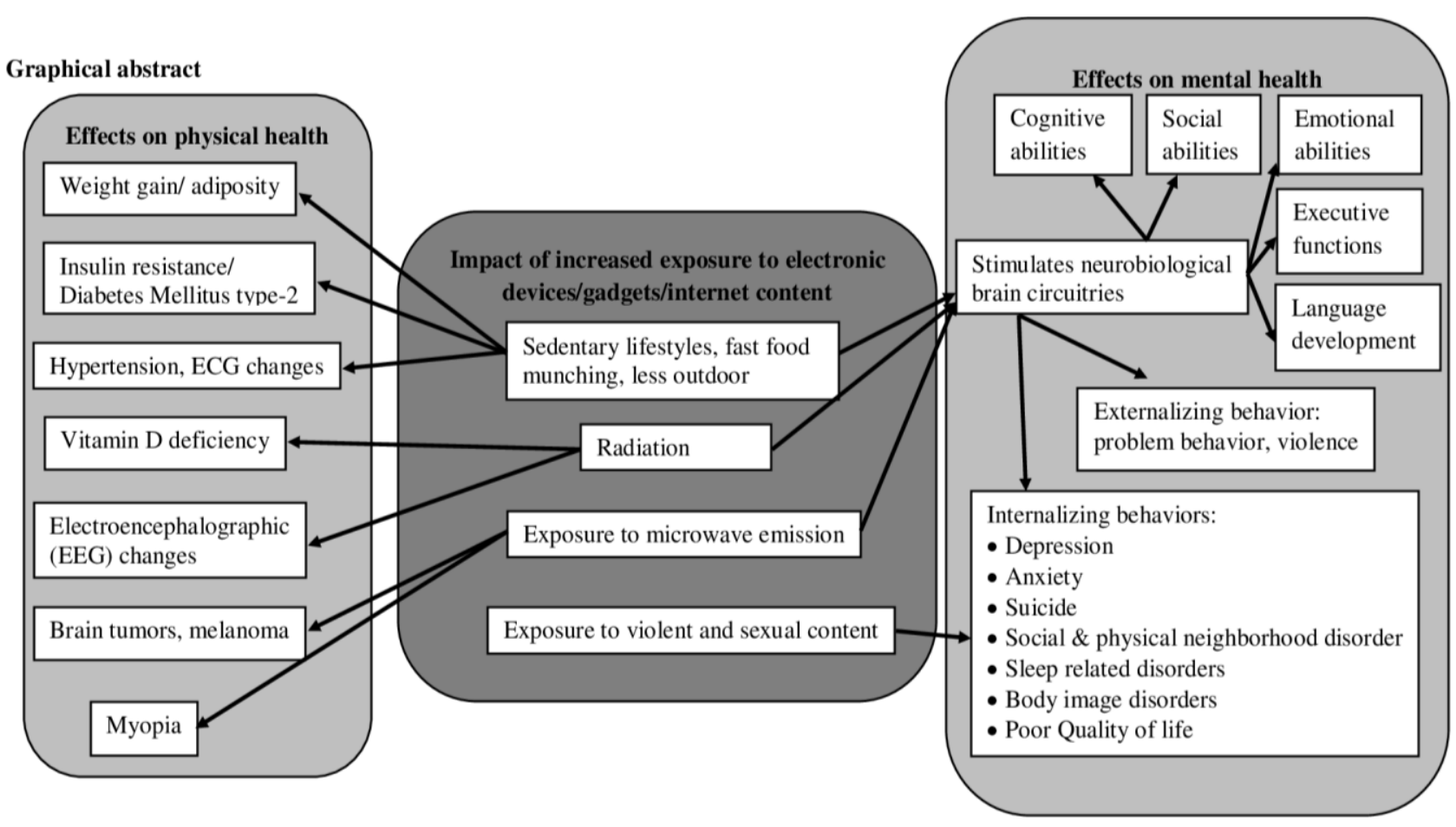

Abstract: Impact of increased exposure to electronic devices/gadgets/internet content on children and adolescents:

The figure explains the ill-effects on health of children and adolescents due to high exposure to electronic devices or internet content. It can cause physical health issues (towards left) as well as mental health issues (towards right).

Figure 1. Health effects

Screen-time corresponds to higher externalizing and internalizing psychopathology. A link between heightened screen-activities with higher levels of depressive symptoms/anxiety/suicide-related outcomes has been found. Children, especially girls, using devices for over five hours/day, nearly half (48\%) might have at least one suicide-related outcome in comparison to approximately one-third (29\%) who has spent an hour/day might have had at least one suicide-related outcome (Twenge et al. 2018). High social and physical neighborhood disorder (neighbors taking advantage, drugs/ drinking in public, crime, etc.) is associated with $40-60 \%$ increased likelihood of electronic-device usage. Those watching television are at greater risk for violent behaviors including physical fight, victim and bully, lowered selfesteem, and addictions, slowed learning, and higher risk of premature cognitive decline (Carson \& Janssen 2012). Internet usage, particularly pornography websites, video gaming (behavioral addiction) has surged during lockdown (Király at al. 2020). Viewing pornography is increasingly seen as a normal stage of development and is linked to poorer attachment to peers and family (Jassogne \& Zdanowicz 2020). Mass-media effect bodyimage and disordered eating, too (Holland \& Tiggemann 2016). Screen-time is adversely associated with sleephealth, disrupted circadian-rhythm, tiredness, and poorer quality of life (Oswald et al. 2020) (Figure 1).

Screen-time consequents decline in overall academic performance (especially mathematics). Students with learning difficulties and ADHD symptoms are more distractive during the online classes vis-à-vis classroom classes, due to lack of supervision.

The socio-economically disadvantaged groups, like rural inhabitants, low-family-income, with poor network connection, technologically-challenged, are deprived from the online-learning. This may widen the urbanrural/rich-poor gap, reduce self-esteem and consequently, marginalization.

\section{SUGGESTIONS AND STRATEGIES FOR HEALTHY SCREEN-HABITS}

COVID-19-pandemic 'high-tech' era, however, may result in some propitious evolution. Accepting the "digital new-norm" by students, teachers and parents may enhance productivity and bring adaptive changes. Motivation to learn new technology may grow among the reluctant ones. The policies should be directed to widen the coverage of internet.

However, current scenario is unclear about the continuation of online learning with the help of gadgets in near future. This has made the situation further, dicey. Safety measures to protect children from being vulnerable online, actively monitoring the content watched or co-viewing or family-viewing may help the guardians. Some parents believe that the increase in onlinelearning is beneficial for children. So, appropriate 
parental guidance programs and policies with an aim to enhance awareness regarding risks and benefits of screen-time, guidance to maintain a balance to scaffold children's screen-time is the call of hour. Awareness programs should target understanding the child, their maturity level, age-appropriate watching, impulsivity, risk factors making them more vulnerable for problemuse, setting family-rules for screen-time, modelling judicious and optimal use of technology, and healthy screen habits and, make them understand healthhazards of screen-time and encouraging digital literacy (Lynch 2017, The Australian Parenting Website 2020). Managing child's expectations about the screen time, framing daily routine, involving their choices for screen-time and planning transitions for comfortably finishing screen-time may help in implementing strategies to control screen-time (The Australian Parenting Website 2020). Promotion of outdoor activities by maintaining the COVID precautionary measures may decrease inclination of children for video-games and significant exposure to social media. Parental control apps to block or filter internet content may be fruitful (Mayo Clinic. Screen time and children 2020). Regular monitoring for total screen-time and maintaining a record of it, may help in early detection of problemuse. Early health-seeking and hence, detection and management of adverse health-effects in the children will be beneficial. Clinicians should obtain history of screen-time in children and adolescents during hospital visits and educate regarding ill-effects of screen-time exposure. Assessment of pathological internet-use should be done. Cognitive-behavioral approach of treatment and family therapy (addresses dysfunctional family) are possible treatment options, too (Young 1999).

\section{CONCLUSION}

Online learning during COVID-19 pandemic in the digital era has warranted enhanced screen-time and brought a "digital new-norm", especially for children and adolescents. Excessive screen-time sprouts plethora of physical and mental health consequences, more-so for this vulnerable group. Awareness about these deleterious effects among guardians, teachers and policy-makers is required. Greater emphasis on early detection of those at-risk and prompt management of these ill-health effects is the call of time. Appropriate measures like awareness programs for carers and educating them for judicious use of technology during the pandemic and post-pandemic era, is of paramount importance.

\section{Acknowledgements: None.}

Conflict of interest: None to declare.

\section{Contribution of individual authors:}

Bichitra Nanda Patra: designing of the concept and literature search, revising it critically for important intellectual content, and final approval of the version to be published.

Kumari Rina: literature searches, manuscript writing, and final approval of the version to be published.

Susanta Kumar Padhy: conception of the manuscript, revising it critically for important intellectual content, and final approval of the version to be published.

\section{References}

1. Ahamed VIT, Karthick NG \& Joseph PK: Effect of mobile phone radiation on heart rate variability. Comput Biol Med 2008; 38: 709-12

2. Bhargava E: How To Take Care Of Mental Health Among Children During Pandemic. Outlook Poshan [Internet]. 09 Nov 2020 [cited 29 Nov 2020]. Available from: https://poshan.outlookindia.com/story/india-newshow-to-take-care-of-mental-health-among-childrenduring-pandemic/363858

3. Carson V \& Janssen I: Neighborhood disorder and screen time among 10-16 year old Canadian youth: A crosssectional study. Int J Behav Nutr Phys Act 2012; 9: 66.

4. Das $S$, Chakraborty $S$ \& Mahanta B: A study on the effect of prolonged mobile phone use on pure tone audiometry thresholds of medical students of Sikkim. J Postgrad Med 2017; 63: 221-5

5. Domingues-Montanari S: Clinical and psychological effects of excessive screen time on children. J Paediatr Child Health 2017; 53:333-8

6. Hardell L, Carlberg $M$ \& Hansson Mild K: Epidemiological evidence for an association between use of wireless phones and tumor diseases. Pathophysiology 2009; 16:113-22

7. Holland $G$ \& Tiggemann M: A systematic review of the impact of the use of social networking sites on body image and disordered eating outcomes. Body Image 2016; 17:100-10

8. Jassogne C\& Zdanowicz N: Real or Virtual Relationships: Does It Matter to Teens?. Psychiatr Danub 2020; 32(Suppl 1):172-5

9. Kaur N, Gupta M, Malhi P, Grover S: Screen Time in Under-five Children. Indian Pediatrics 2019; 56: 773-88

10. Király O, Potenza MN, Stein DJ, King DL, Hodgins DC, Saunders JB et al.: Preventing problematic internet use during the COVID-19 pandemic: Consensus guidance. Compr Psychiatry 2020; 100: 152180

11. Lynch M: 18 Ways to Manage Your Kid's Screen Time. Pedagogue. The Tech Edvocate [Internet]. 10 May 2017 [cited 11 Dec 2020]. Available from:

https://www.thetechedvocate.org/screen-time-management/

12. Managing screen time: children 3-11 years: Raising Children Network [Internet]. 21 Dec 2020 [cited 11 Dec 2020]. Available from: https://raisingchildren.net.au/ preschoolers/play-learning/screen-time-healthy-screenuse/managing-screen-time-3-11-years

13. Mayo Clinic. Screen time and children: How to guide your child - Mayo Clinic [Internet]. 20 Jun 2019 [cited 11 Dec 2020]. Available from: https://www.mayoclinic.org/healthylifestyle/childrens-health/in-depth/screen-time/art-20047952 
14. Nightingale CM, Rudnicka AR, Donin AS, Sattar N, Cook $D G$, Whincup PH et al.: Screen time is associated with adiposity and insulin resistance in children. Arch Dis Child 2017; 102: 612-616

15. Oswald TK, Rumbold AR, Kedzior SGE, Moore VM: Psychological impacts of "screen time" and "green time" for children and adolescents: A systematic scoping review. PLoS One 2020; 15: e0237725

16. Roggeveen $S$, VanOs J, Viechtbauer W, Lousberg R: EEG changes due to experimentally induced $3 G$ mobile phone radiation. PLoS One 2015; 10: e0129496

17. Twenge JM, Joiner TE, Rogers ML, Martin GN: Increases in Depressive Symptoms, Suicide-Related Outcomes, and Suicide Rates Among U.S. Adolescents After 2010 and Links to Increased New Media Screen Time. Clin Psychol Sci 2018; 6:3-17
18. Verma P: COVID-19 Impact: Screen time up by $100 \%$ for children. The Economic Times [Internet], 15 Jun 2020 [cited 29 Nov 2020]. Available from:

https://economictimes.indiatimes.com/industry/services/ed ucation/covid-19-impact-screen-time-up-by-100-forchildren/articleshow/76383951.cms? from $=m d r$

19. Wai Wong C, Tsai A, Jonas JB, Chen J, Ang M, Ting DSW et al.: Digital Screen Time During COVID-19 Pandemic: Risk for a Further Myopia Boom? Am J Ophthalmol 2020; S0002-9394(20)30392-5

20. Young KS: Internet addiction: symptoms, evaluation and treatment. In: VandeCreek L, Jackson TL (Eds) Innovations in clinical practice. Sarasota, Florida, 351-2. Professional Resource Press/Professional Resource Exchange, 1999
Correspondence:

Kumari Rina, MD, PhD

All India Institute of Medical sciences

Bhubaneswar, Odisha, India

E-mail:drkumaririna@gmail.com 